\title{
MICROSTRUCTURAL STABILITY AND CRACK GROWTH BEHAVIOUR OF A POLYCRYSTALLINE NICKEL-BASE SUPERALLOY.
}

\author{
D. W. Hunt, D. K. Skelton, and D. M. Knowles.
}

\author{
Rolls Royce University Technology Centre \\ Dept. Materials Science \& Metallurgy \\ University of Cambridge.
}

\begin{abstract}
$\underline{\text { Abstract }}$
In this paper the microstructural instability of a recently developed powder-processed alloy, RR1000, is investigated and the corresponding influence on the creep-fatigue crack growth behaviour scrutinised. Equilibrium phase calculations of the alloy composition predict the presence of the TCP (Topologically Close Packed) phase sigma at the intended operating temperature of the alloy. Subsequent exposures at elevated temperatures reveal intergranular sigma phase precipitation. The kinetics of sigma phase formation has been determined experimentally by quantitative x-ray diffraction of exposed specimens. The effect of this grain boundary modification during prolonged exposure on the mechanical properties of the alloy was then investigated by testing specimens with two thermal histories: as-heat-treated (with a standard solution and ageing heat treatment developed for RR1000) and exposed to contain $1 \mathrm{wt} \%$ sigma phase on the grain boundaries.
\end{abstract}

To enable the discrimination of creep and environmental damage mechanisms during crack growth, fatigue and sustained load crack growth tests were performed in both vacuum and air. The influence of exposure on tensile and creep rupture behaviour was also investigated. In order to provide a suitable reference, a single fatigue crack propagation test was performed on the as-heat-treated material at room temperature. All other tests were performed at $725^{\circ} \mathrm{C}$. From the crack growth rates recorded and fractographic studies it is concluded creep and environmental mechanisms are responsible for increases in crack growth rates observed when the temperature is increased from $20^{\circ} \mathrm{C}$ to $725^{\circ} \mathrm{C}$. Sigma phase precipitation during alloy exposure increases the severity of creep and environmental processes leading to increases in crack growth rates. 


\section{Introduction}

The demand for increased service lives and operating temperatures of gas turbine engines has led to the design and use of turbine disc alloys of increasing chemical complexity. Many latest generation alloys are increasingly unstable at the intended operating temperatures. In order to maximise the engineering performance of such alloys a comprehensive understanding of the influences of microstructural instability on the mechanical properties is required.

In this study a recently developed disc alloy, RR $1000^{[1]}$, has been assessed. Thermo-calc software ${ }^{[2]}$ together with a thermodynamic databank $^{[3]}$ was used to predict the equilibrium phase composition of the alloy, which includes the TCP (Topologically Close Packed) phase sigma. The presence and effect of sigma in other nickel-base superalloys has been noted by various researchers ${ }^{[4-8]}$. Substantial decreases in ductility and creep rupture lives have been reported. The severity of property degradation previously observed appears to be sensitive to the morphology of sigma phase ${ }^{[4]}$. Needles, platelets or continuous intergranular films are proposed to be more deleterious than a discrete, more equiaxed intragranular morphology. Some mechanisms accounting for observed property losses have been suggested ${ }^{[8]}$. A hard sigma phase, especially a plate-like or needle morphology on grain boundaries offer ideal sites for crack initiation. TCP phases such as sigma are also rich in refractory elements like chromium, cobalt, molybdenum and tungsten. Precipitation of these phases will result in solute depletion in the surrounding $\gamma$ matrix leading to localised compositional weakening. The susceptibility to environmental attack may likewise be increased if the formation of a protective $\mathrm{Cr}_{2} \mathrm{O}_{3}$ scale is inhibited through chromium depletion.

The effect of sigma phase precipitation on fatigue crack growth, particularly at elevated temperatures, is less clear. In order to assess crack growth at elevated temperatures, it is essential to consider damage mechanisms resulting from fatigue, creep and environmental processes. The relative contribution of these mechanisms will also be influenced by the microstructural state of the alloy.

\section{$\underline{\text { Materials and Methods }}$}

The composition of RR1000 as well as other well-known disc alloys is presented in table I.

Table I. Composition (wt\%, balance nickel) of RR1000 and other disc alloys ${ }^{[1,8]}$.

\begin{tabular}{|c|c|c|c|}
\hline Element & RRI000 & U72OLi & Waspaloy \\
\hline $\mathrm{Cr}$ & $14.35-15.15$ & 16 & 19.5 \\
$\mathrm{Co}$ & $14.0-19.0$ & 15 & 13.5 \\
$\mathrm{Mo}$ & $4.25-5.25$ & 3.0 & 4.3 \\
$\mathrm{~W}$ & - & 1.25 & - \\
$\mathrm{Al}$ & $2.85-3.15$ & 2.5 & 1.3 \\
$\mathrm{Ti}$ & $3.45-4.15$ & 5.0 & 3.0 \\
$\mathrm{Ta}$ & $1.35-2.15$ & - & - \\
$\mathrm{Hf}$ & $0.0-1.0$ & - & - \\
$\mathrm{Zr}$ & $0.05-0.07$ & 0.035 & - \\
$\mathrm{C}$ & $0.012-0.033$ & 0.015 & 0.08 \\
$\mathrm{~B}$ & $0.01-0.025$ & 0.015 & 0.006 \\
\hline
\end{tabular}

Quantitative analysis of sigma phase precipitation kinetics was achieved using bulk electrolytic phase extraction of thermally exposed specimens. The powder-like extracts were examined by $\mathrm{X}$-ray diffraction. Diffraction data was quantified as mass fraction phase using Quasar software ${ }^{[9]}$ coupled to a crystallographic database. This technique is based on the Rietveld Method ${ }^{[10]}$. Data gathered by this procedure was used to construct TTT curves for sigma phase precipitation. The effect of the measured microstructural instability on the creep-fatigue behaviour of RR1000 was assessed by testing material in the as-heat-treated condition in comparison to exposed test pieces. In order to precipitate sigma phase within convenient time periods, specimens were exposed above the perceived operating temperature of RR1000. The exposed material contained 1 wt $\%$ sigma phase following a heat treatment equivalent to the nose position of the TTT curve determined as described. In order to differentiate fatigue, creep and environmental damage mechanisms occurring during crack growth at elevated temperatures, fatigue and sustained load crack propagation tests were carried out in vacuum and air at $725^{\circ} \mathrm{C}$. A $1-1-1-1$ trapezoidal waveform with $\mathrm{R}=0.5$ was used for fatigue tests. SENB (single edge notch bend) specimens were used for both fatigue and sustained load testing. The crack length was monitored using the d.c. potential drop method ${ }^{[11]}$. The influence of exposure on the creep rupture and tensile behaviour of the alloy was also investigated at $725^{\circ} \mathrm{C}$.

\section{Microstructural Stability}

Examination of the microstructure after solutioning and ageing heat treatments reveals a fine grain size (typically $8-12 \mu \mathrm{m}$ ) with a blocky primary $\gamma^{\prime}$ situated on the grain boundaries and a fine intergranular secondary $\gamma^{\prime}$ with an average size of $225 \mathrm{~nm}^{[12]}$. A general view of the microstructure, showing primary $\gamma^{\prime}$ and grain structure, is shown in figure 1 . No sigma phase can be detected in the as-heat-treated alloy.

Subsequent prolonged exposure at elevated temperatures leads to the intergranular precipitation of sigma phase, developing extensive grain boundary networks after lengthy treatments. This microstructural degradation of RR1000 is shown in figures 2 and 3. The 'nose' of the TTT curve, illustrated in figure 4, was found to be significantly higher than the perceived maximum operating temperature of RR 1000.

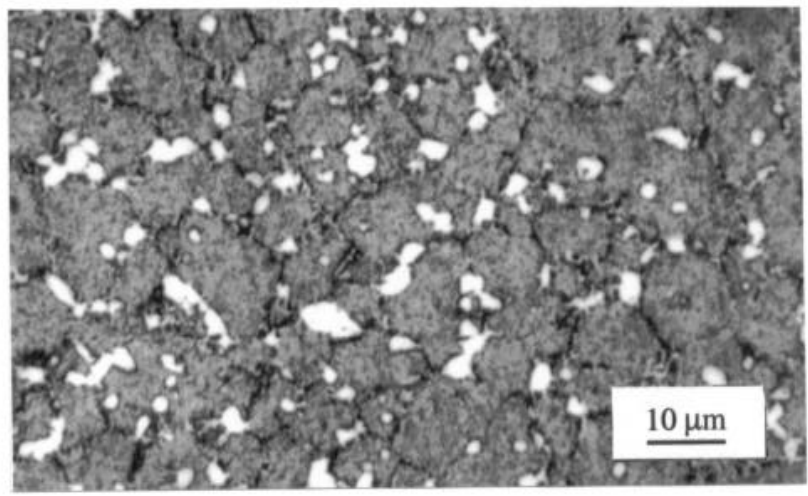

Figure 1. Optical micrograph of RR1000 showing an equiaxed grain structure (size $8-12 \mu \mathrm{m}$ ) with primary $\gamma^{\prime}$ situated on the grain boundaries. The secondary intragranular $\gamma^{\prime}$ may only discerned at higher magnification. 


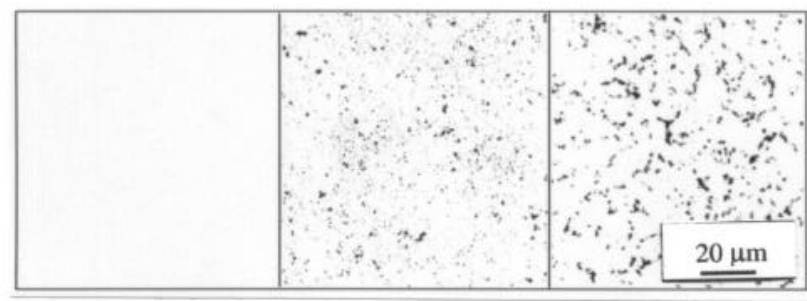

Figure 2. Optical micrographs similarly etched to reveal the extent of sigma phase precipitation during prolonged exposures at elevated temperatures. Image on left shows the as-heat-treated condition. No sigma phase is detected either through microscopical examination or $\mathrm{x}$-ray diffraction analysis.

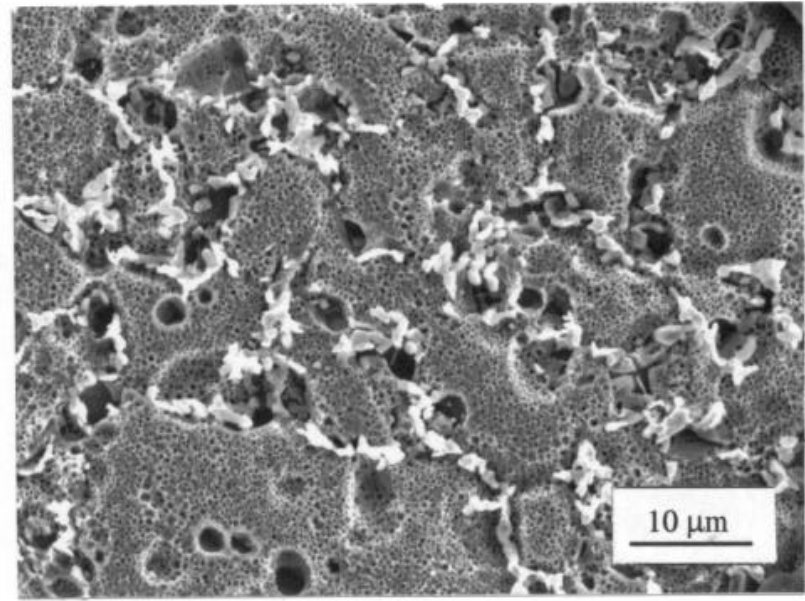

Figure 3. Deep-etched micrograph showing white sigma phase precipitates along the grain boundaries.

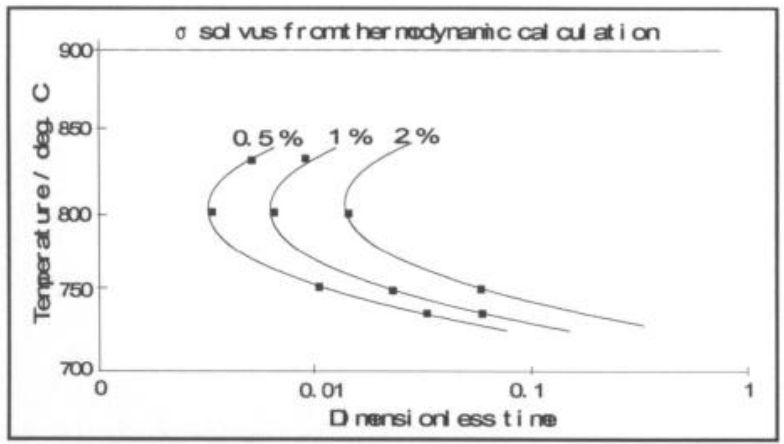

Figure 4. Experimentally determined TTT curves for sigma phase precipitation in RR1000.

Apart from intergranular precipitation of sigma phase it is possible that prolonged elevated ageing treatments may result in coarsening of fine secondary $\gamma^{\prime}$ precipitates. Examination of $\gamma^{\prime}$ using carbon extract replicas was carried out of a specimen exposed to approximately the nose position of the 2 wt $\%$ curve in figure 4 . The average $\gamma^{\prime}$ particle size over this period was found to be
$228 \mathrm{~nm}$ (average size in the as-heat-treated alloy was measured as $225 \mathrm{~nm})$.

\section{Mechanical Properties}

\section{Tensile Strength}

The tensile behaviour as a function of temperature and alloy exposure is plotted on normalised axes in figure 5 .

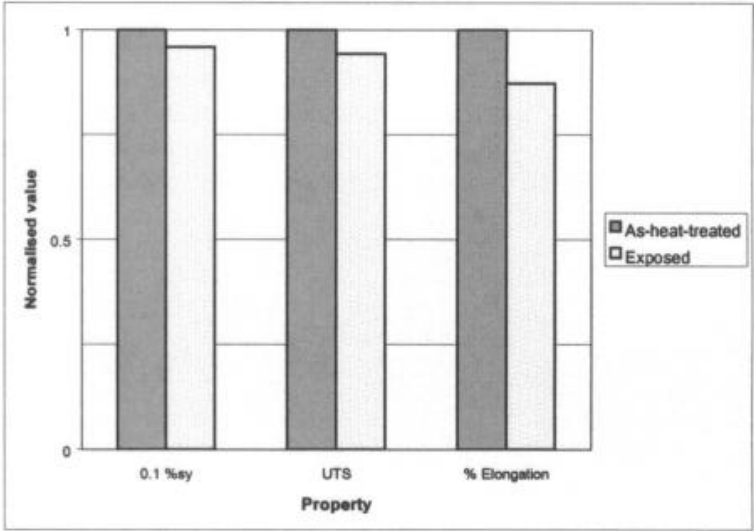

Figure 5. Tensile properties $\left(0.1 \% \sigma_{y}\right.$, UTS and elongation) of RR1000 at $725^{\circ} \mathrm{C}$ as a function alloy exposure.

Yield strength, UTS and ductility are reduced for the exposed condition. The effect on ductility is notable with the elongation being decreased by $13 \%$ whilst the yield strength is reduced by just $4 \%$. The ultimate tensile strength of the exposed test-piece is decreased by $6 \%$.

\section{Creep Rupture}

The effect of alloy exposure on the creep properties of RR1000 is shown in figures 6 and 7.

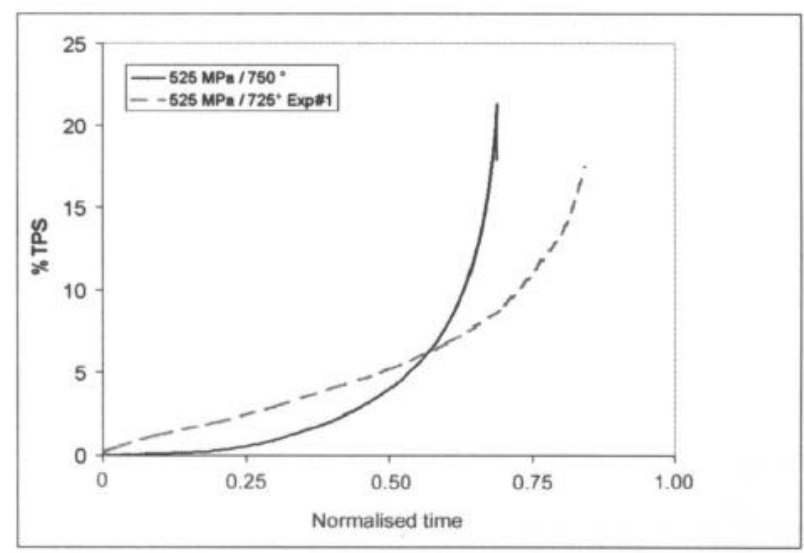

Figure 6. Creep curves demonstrating modification in strain evolution of the exposed alloy. It should be noted that in this case, creep data for the as-heat-treated alloy is for $750{ }^{\circ} \mathrm{C}$ not $725^{\circ} \mathrm{C}$. 


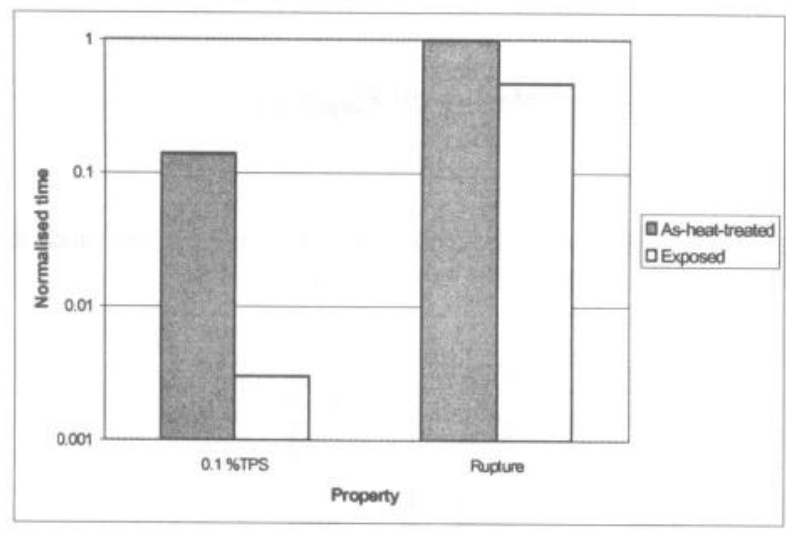

Figure 7. The influence of exposure on the creep properties of RR1000. In this instance data at $725^{\circ} \mathrm{C}$ is used for the as-heattreated alloy. Notice the significant effect on the creep strain rate at low TPS (total plastic strain).

Whilst the rupture life by is reduced by $53 \%$, it is the effect on early strain rates which is most conspicuous with the time to $0.1 \%$ TPS decreased by $97 \%$. The higher secondary creep rates are clearly visible in figure 6.

\section{Fatigue Crack Growth}

The crack growth rates recorded during fatigue testing RR1000 are shown in figure 8.

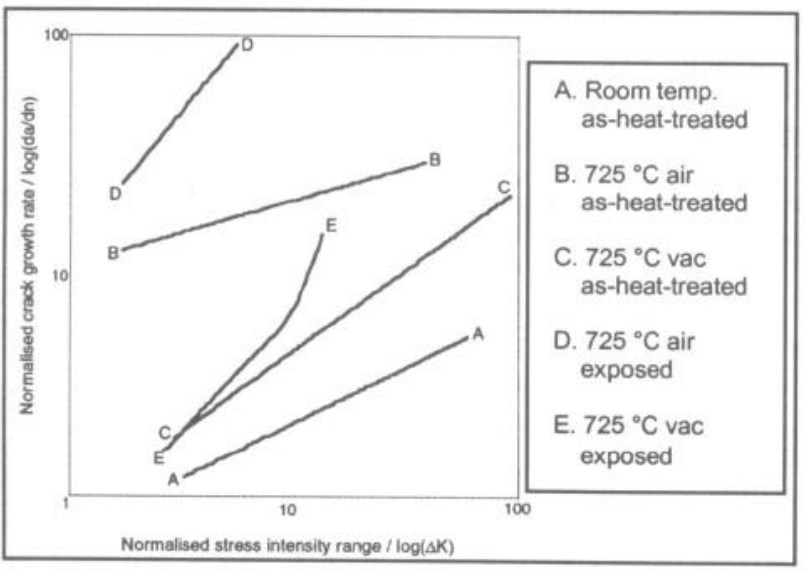

Figure 8. Fatigue crack propagation in RR1000 as a function of temperature, environment and microstructure. A balanced trapezoidal waveform (1-1-1-1, $0.25 \mathrm{~Hz}, \mathrm{R}=0.5)$ was utilised.

The effect of temperature and environment is striking during fatigue crack propagation in RR1000. An order of magnitude increase in crack growth rate is observed when the temperature is increased to $725{ }^{\circ} \mathrm{C}$ (curves A and B). The influence of environment, particularly at low $\Delta \mathrm{K}$, is also dramatic (curves $\mathrm{B}$ and $\mathrm{C}$ ). Exposure of RR1000 results in an extensive increase in crack growth rate, especially in air (curves B and D). The crack growth rates recorded in the exposed alloy in vacuum at low $\Delta \mathrm{K}$ are similar to the as-heattreated specimen (curves C and E). However, the Paris slope in vacuum is significantly higher and the crack growth rates diverge substantially.

\section{Sustained Load Crack Growth}

Crack growth resulting from a sustained load is shown in figure 9.

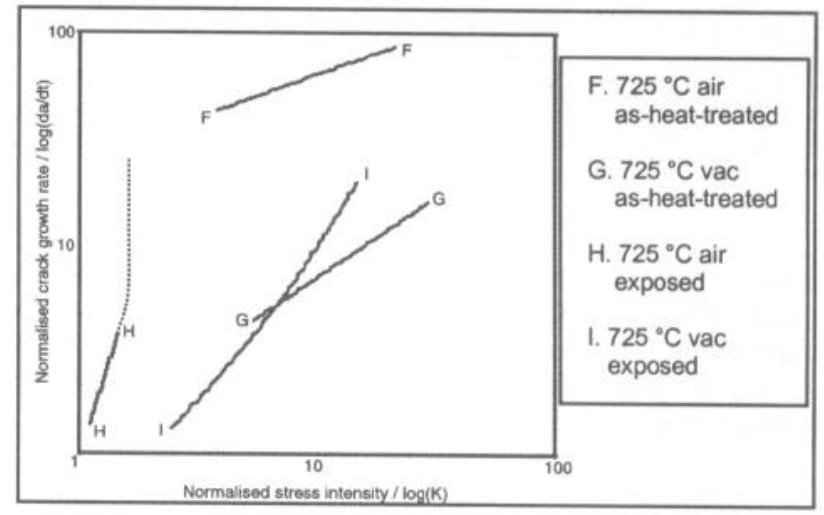

Figure 9. The influence of environment and exposure on the sustained load crack growth rate in RR1000. It should be noted that the extreme sensitivity of the exposed specimen in air resulted in rapid failure at relatively low stress intensities and the very high crack growth rates attained could not be readily recorded.

The influence of environment is also apparent during sustained load crack growth. The presence of sigma phase in the exposed specimens has a dramatic effect, particularly in an oxidising environment. The effect of sigma phase precipitation in air is extreme with very little crack growth and rapid failure over the stress intensity range tested. In vacuum, the exposed specimen has similar crack growth rates at lower values of $\mathrm{K}$ although initiating crack growth at very low stress intensities proved to be difficult to achieve with test-pieces in the as-heat-treated condition.

\section{Discussion}

\section{Microstructural Degradation}

Prolonged exposure of RR1000 over the temperature range examined results in a transformation of the grain boundary microstructure. No significant change in the average $\gamma^{\prime}$ size could be detected up to an exposure resulting in $2 \mathrm{wt} \%$ sigma phase (i.e. significantly greater than that of specimens used for mechanical property degradation assessment). The discrete intergranular precipitation of sigma phase may therefore said to be associated with the property changes which were recorded in RR 1000 .

\section{Crack Growth Behaviour}

The test results gathered during this study validate the proposition that crack growth in $\mathrm{RR} 1000$ at $725^{\circ} \mathrm{C}$ can arise due to fatigue, creep and environmental mechanisms. The grain boundary modification brought about by sigma phase precipitation during prolonged exposure alters the relative contribution of these. The environmental and creep contributions may be distinguished by consideration / comparison of the crack growth tests performed in vacuum and air at $725^{\circ} \mathrm{C}$. It is assumed that the level of vacuum achieved during the tests (typically $\mathrm{pO}_{2}=10^{-7} \mathrm{mbar}$ ), whilst from a thermodynamic consideration not low enough to preclude $\mathrm{Cr}_{2} \mathrm{O}_{3}$ or $\mathrm{NiO}$ formation, is sufficient to suppress the environmental effects observed during air tests. 
During vacuum tests of the as-heat-treated material the extent of creep damage is sensitive to the stress intensity range, $\Delta K$, in fatigue tests or stress intensity, $\mathrm{K}$, in sustained load tests. This is supported by the difference in fracture morphology demonstrated at room temperature and $725^{\circ} \mathrm{C}$ vacuum as shown in figures 10 and 11.

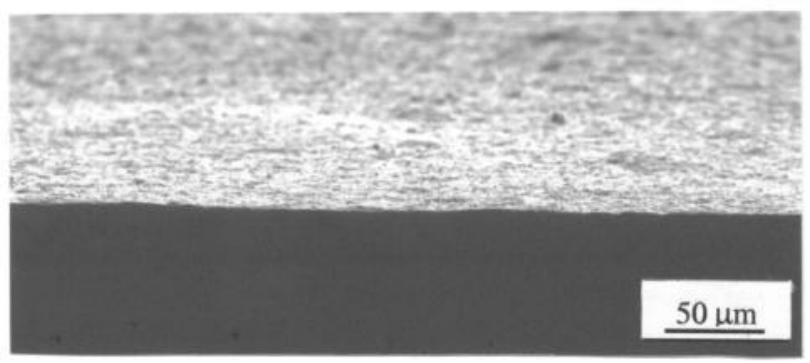

Figure 10. Fracture surface of room temperature fatigue specimen, demonstrating transgranular failure at all $\Delta \mathrm{K}$.

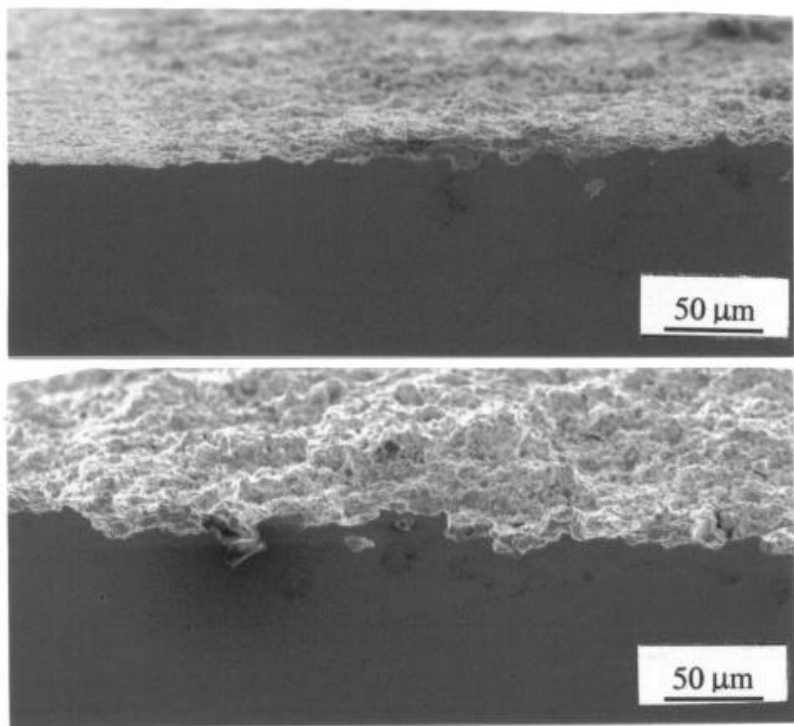

Figure 11. Fatigue fracture surfaces developed during crack growth in vacuum. Top shows low $\Delta K$ with pre-crack, high $\Delta K$ is shown in the bottom image.

At room temperature in an ambient environment crack growth may be said to be due to purely fatigue mechanisms, and the fracture morphology is transgranular at all values of $\Delta \mathrm{K}$ (figure 10). At $725^{\circ} \mathrm{C}$ in vacuum, a progressive transition to intergranular fracture occurs as $\Delta \mathrm{K}$ (and $\mathrm{K}_{\max }$ ) increases whilst the crack growth rates recorded demonstrate an increased sensitivity to $\Delta K$. During sustained load crack growth, where the fatigue contribution is removed, fracture proceeds in an intergranular manner. Furthermore, creep strain investigations performed elsewhere ${ }^{[12]}$ have shown that creep damage in RR1000 develops via intergranular cavitation. The increase in Paris slope during crack growth in vacuum is notable. At low $\Delta \mathrm{K}$ the absolute crack growth rates are similar to that observed at room temperature where damage resulting in crack growth originates from purely fatigue processes. At $725{ }^{\circ} \mathrm{C}$, creep mechanisms become significant. Static, or time dependent events contributing to crack growth have been studied elsewhere ${ }^{[13-15]}$. The creep contribution observed in crack growth in RR1000 at $725^{\circ} \mathrm{C}$ may be similarly rationalised as increasing the Paris exponent, $\mathrm{m}$.

The effect of intergranular sigma phase precipitation during alloy exposure on the creep contribution is quite dramatic. Evidence from tensile tests of the exposed material suggest that whilst yield strength is not greatly influenced, there is an appreciable degree of embrittlement which is evident from the reduction in tensile elongation. The strain evolution during creep testing is also significant. Given the modification in creep behaviour, an acceleration of crack growth rates in vacuum is anticipated. Figure 12 shows the fracture morphology of the exposed alloy when fatigue tested in vacuum. Although the absolute values of crack growth rate at low $\Delta \mathrm{K}$ in the exposed material (figure 8) is similar to that recorded in the as-heat-treated alloy, the extent of creep damage appears to be increased. Fracture appears to be intergranular at all values of $\Delta K$ and the crack growth rate displays an increased sensitivity to $\Delta K$. This is also evident in the crack growth rates recorded under sustained load in vacuum as shown in figure 9 .
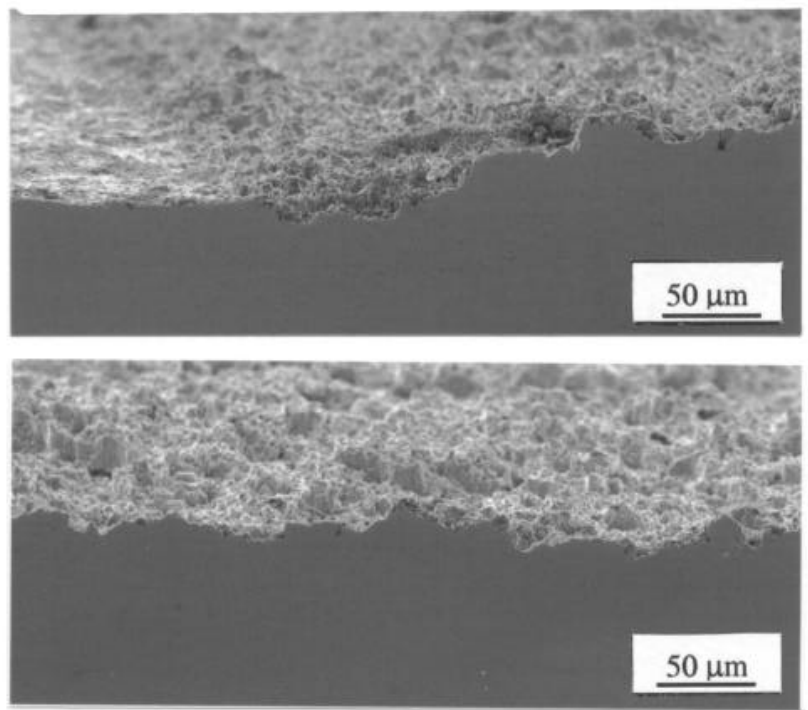

Figure 12. Fracture morphology developed in exposed specimens when fatigue tested in vacuum. The degree of creep damage is increased with intergranular fracture apparent at low $\Delta \mathrm{K}$ as well as high $\Delta \mathrm{K}$ (top and bottom).

Close examination of the crack tip region reveals the nature of damage which leads to the increased sensitivity to creep crack growth. Figure 13 shows a crack tip in the exposed alloy developed under sustained load in vacuum. Failure appears to occur discretely ahead of the main crack tip. These small cracks evolve resulting in fracture as shown in previous figures. In the exposed alloy localised failure appears to occur at the interfaces of sigma phase. An example of this behaviour is shown in figure 14. The influence of grain boundary particles on cavity nucleation during creep has been studied extensively ${ }^{[16]}$, as has the effect of sigma precipitation on creep ductility in other alloys ${ }^{[4,5,8]}$. The mechanisms of local compositional weakening and damage initiation previously proposed $^{[8]}$ are in agreement with the crack growth processes observed in vacuum in RR1000. 


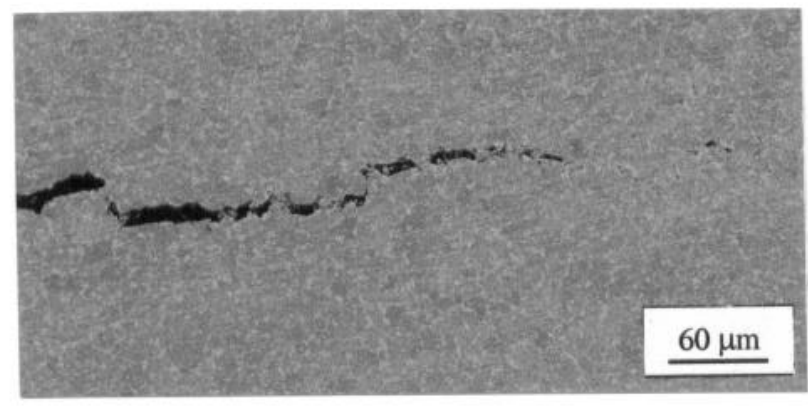

Figure 13. Crack tip from sustained load crack growth under vacuum of the exposed material.

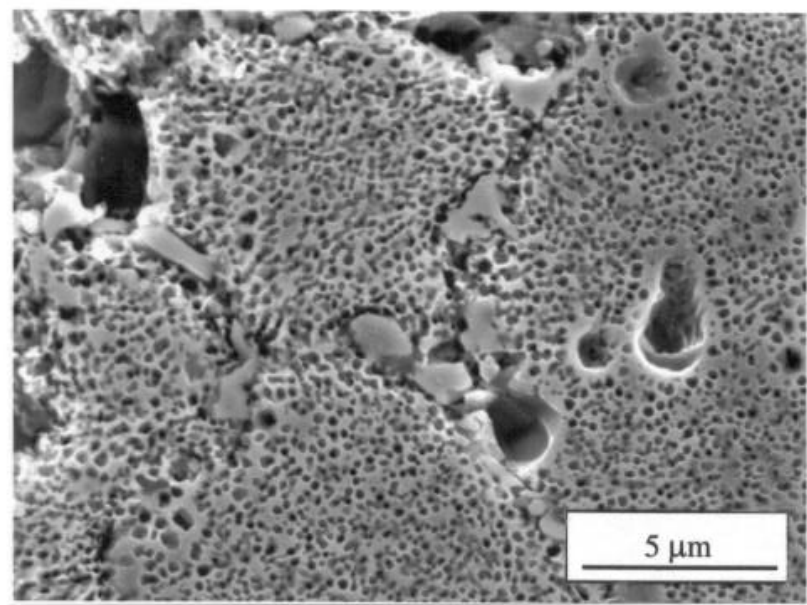

Figure 14. Local failure ahead of the crack tip. Shown is an etched surface to reveal the location of sigma phase. Microstructure appears porous due to the preferential dissolution of $\gamma^{\prime}$ during etching. Sigma phase is visible as unetched discrete precipitates approximately $2 \mu \mathrm{m}$ in size, centrally positioned in the field of view. Short cracks are apparent at the sigma phase interface.

The damage mechanisms leading to crack growth are markedly different during air tests at $725^{\circ} \mathrm{C}$. The environmental effects observed result in substantial increases in crack growth rates. The increases in crack growth rate are concurrent with a transition to intergranular fracture. The fatigue fracture morphology of the asheat-treated material is shown in figure 15.

Crack growth in air at $725^{\circ} \mathrm{C}$ may also be distinguished from the vacuum behaviour by the presence of secondary cracking observed in the test-pieces. This occurred along grain boundaries adjacent the fracture surface. An example of this phenomenon is shown in figure 16 and suggests severe grain boundary embrittlement.
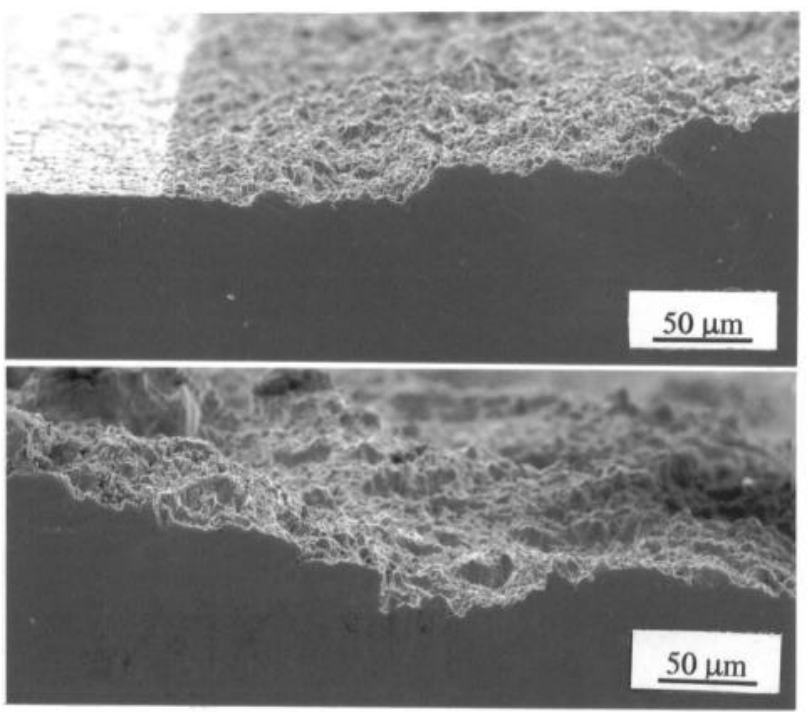

Figure 15. Fatigue fracture surfaces (low and high $\Delta K$ top and bottom respectively) of as-heat-treated RR1000 fatigue tested in air at $725^{\circ} \mathrm{C}$.

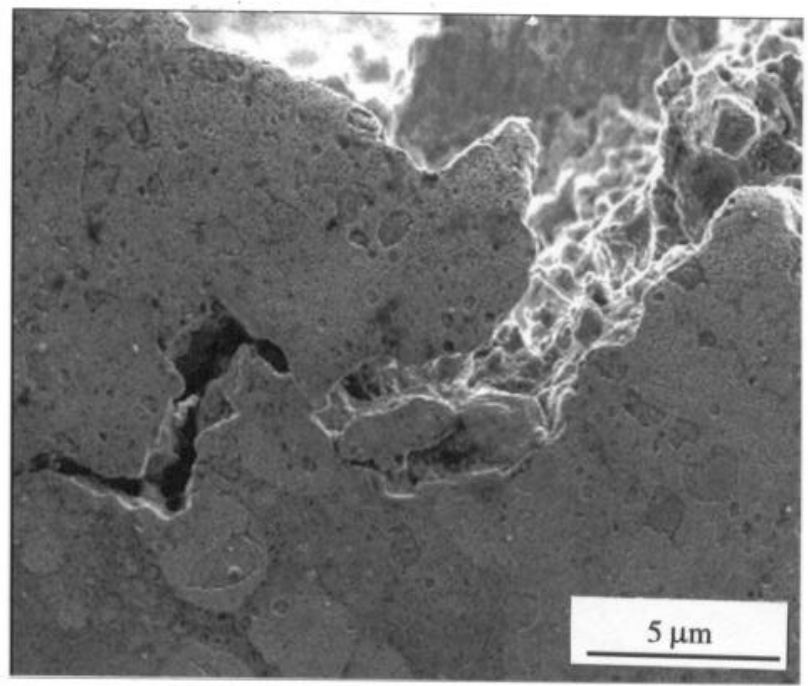

Figure 16. Secondary intergranular cracking observed in specimens tested in air at $725^{\circ} \mathrm{C}$. This phenomenon was not found in vacuum test-pieces.

The dramatic and detrimental effect of an oxidising environment on crack growth has been investigated in other alloy systems ${ }^{[17-20]}$. In particular, the behaviour of alloy 718 has been widely documented. Three mechanisms of oxygen induced embrittlement have been proposed. Short-range oxygen diffusion along grain boundaries may result in oxide intrusions that easily rupture under the constrained geometry of the crack tip and accelerate crack growth. Localised oxygen induced damage may also occur ahead of the crack tip if oxygen is transported to greater distances along the boundaries leading to internal grain boundary oxidation. A third environmental damage mechanism ${ }^{[21]}$ has been proposed involving cavitation ahead of the crack tip. This process may arise due to the oxidation of carbides and the subsequent release of carbon monoxide and/or carbon dioxide. Other investigators ${ }^{[22]}$ have 
reasoned that this mechanism may be inhibited in alloys containing significant quantities of chromium due to the preferential formation of $\mathrm{Cr}_{2} \mathrm{O}_{3}$.

The dramatic environmental assisted acceleration is also observed during sustained load crack growth in air at $725{ }^{\circ} \mathrm{C}$. The mechanistic influence of sigma phase from an environmental consideration is less clear than that of creep. Precipitation of sigma phase dramatically increases the fatigue crack growth rates recorded in air. Again, this increase is associated with further intergranular embrittlement. The fatigue fracture surfaces of the exposed testpieces are shown in figure 17. Although increasingly subtle, more extensive intergranular embrittlement and fracture is discernible. The extent of secondary cracking as shown in figure 16 is also significantly increased supporting this observation.
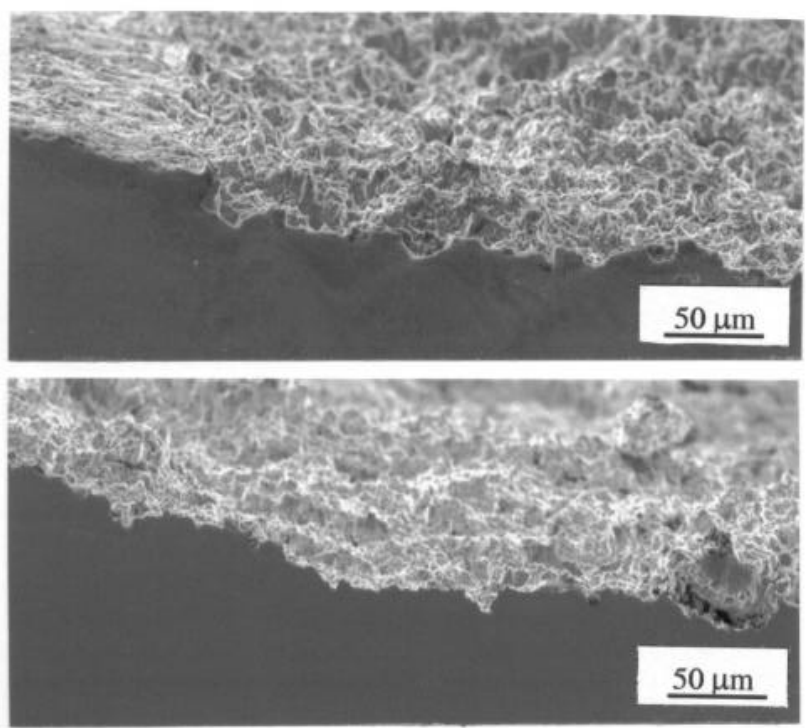

Figure 17. Fatigue fracture surfaces of exposed alloy in air at $725^{\circ} \mathrm{C}$. The extent of intergranular embrittlement is increases over that observed in the as-heat-treated material.

The crack growth rates recorded from the sustained load test of the exposed alloy (figure 9, curve $\mathrm{H}$ ) are the cause of some confusion. The absolute values of crack growth rate recorded are quite low. However, the rapid fracture which occurred in this specimen prevented accurate measurement of the crack growth rates achieved. It seems that this test was conducted very close to a critical stress intensity for the exposed alloy at this temperature and requires further investigation.

Unlike the localised creep damage ahead of the crack tip observed in vacuum, the environmental mechanism leading to accelerated crack growth in air appears to be one of intergranular oxidation at the crack tip. The crack tip from an interrupted sustained load test of the exposed alloy is shown in figures 18 and 19. This clearly indicates the extensive oxidation which occurs at the crack tip and dominates the crack growth rates recorded. This contrasts sharply with the observations in vacuum voiding ahead of the crack tip was observed.

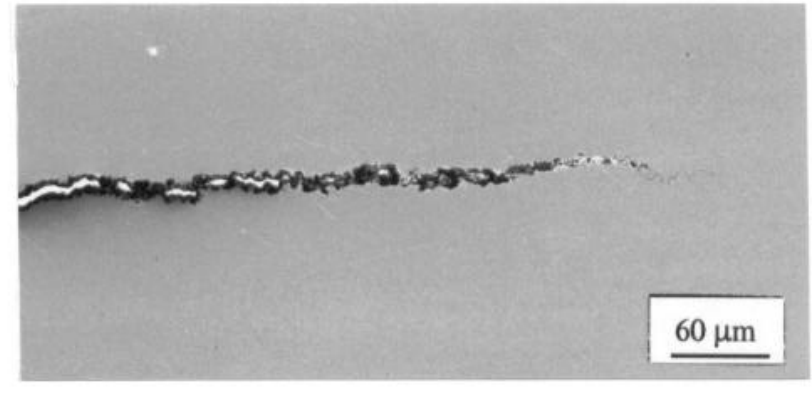

Figure 18. Crack tip in the exposed material due sustained load in air at $725^{\circ} \mathrm{C}$

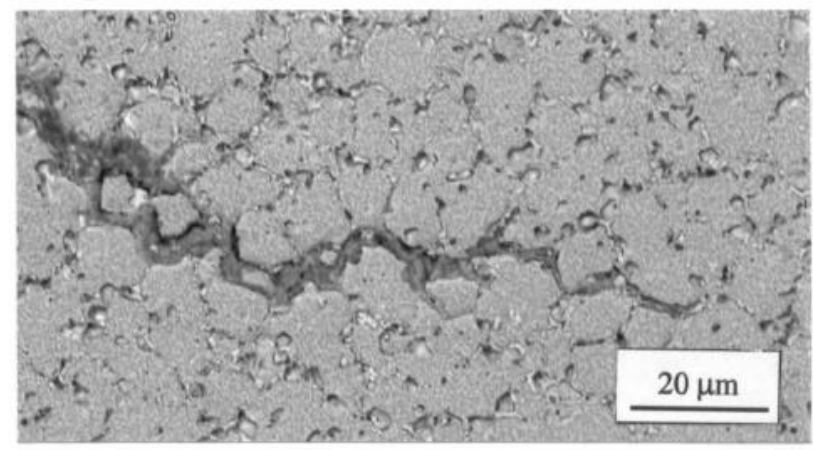

Figure 19. Extensive intergranular oxidation ahead of the crack tip.

The mechanism of oxidation observed appears to be in broad agreement with models of intergranular oxidation previously proposed for crack tip oxidation. No evidence of discrete oxidation ahead of the crack tip was found during this investigation. The precise mechanism by which sigma phase contributes to this intergranular oxidation is not certain as of yet, however it seems likely that solute (in particular chromium) depletion effects are responsible for the increased susceptibility to environmental attack.

\section{Conclusions}

Prolonged thermal exposure of RR1000 leads to intergranular precipitation of sigma phase which has been experimentally characterised in the form of TTT curves. This grain boundary modification leads to quite dramatic changes in the mechanical properties of the alloy.

At $725{ }^{\circ} \mathrm{C}$ crack growth due to time dependent mechanisms of creep and oxidation result in a modification in fracture behaviour, namely a transition from ductile transgranular fracture associated with pure fatigue to intergranular fracture. These transient effects have been investigated by examining the crack growth behaviour during sustained load tests. The creep mechanism displays an increased sensitivity to crack tip stress over oxidation processes. However, in terms of the contribution to absolute crack growth rates over the stress intensity range tested environmental mechanisms dominate at $725^{\circ} \mathrm{C}$. Sigma precipitation increases the severity of both creep and environmental mechanisms leading to increased crack growth rates. Creep damage in exposed specimens is associated with localised failure at the sigma interface. In air at $725^{\circ} \mathrm{C}$ intergranular oxidation appears to be responsible for the crack growth rate increases recorded. 


\section{Acknowledgements}

The authors gratefully acknowledge the Engineering and Physical Science Research Council, Rolls Royce plc. and DERA for their financial support and provisional of material.

\section{$\underline{\text { References }}$}

1. S. J. Hessell et al, "Nickel Alloy for Turbine Engine Components", United States Patent, Number 5897718 (27 April 1999).

2. Bo Sundmann, Thermo-calc Users' Guide (Stockholm, Sweden: Division of Computational Thermodynamics, Department of Materials Science \& Engineering, Royal Institute of Technology, Stockholm, Jan. 1997.)

3. Rolls Royce Aerospace Group, Thermodynamic Database for Nickel-base Superalloys, Rolls Royce plc, Derby U.K., 1999.

4. J. R. Mihalisin, C. G. Bieber, and R. T. Grant, "Sigma-Its Occurrence, Effect, and Control in Nickel-Base Superalloys", TMS AIME, 242, Dec 1968, 2399-2414.

5. G. Chen et al, "Grain Boundary Embrittlement by $\mu$ and $\sigma$ Phases in Iron-Base Superalloys", Proceedings of the $4^{\text {th }}$ International Conference on Superalloys, 1980, Ed. J. K. Tien et al, TMS, Seven Springs PA, (1980), 323-333.

6. P. W. Keefe, S. O. Mancuso, and G. E. Maurer, "Effects of Heat Treatment and Chemistry on the Long-Term Phase Stability of a High Strength Nickel-Based Superalloy", Proceedings of the $7^{\text {th }}$ International Symposium on Superalloys, Ed. S. D. Antolovich et al, TMS, Seven Springs PA, (1992), 487-496.

7. G. F. Vander Voort and H. M. James, "Wrought HeatResistant Alloys", Metals Handbook, vol. 9, (American Society for Metals, 1985), 308-313.

8. C. T. Sims, N. S. Stoloff, and W. C. Hagel, eds., Superalloys II. High Temperature Materials for Aerospace \& Industrial Power (New York, NY: John Wiley \& Sons inc., 1987), 221226.

9. Philips Electronics N.V., Quasar Version 1.0. Software for Quantitative Standardless Analysis using the Rietveld Method. User's Guide, December 1994.

10. D. L. Bish and S. A. Howard, "Quantitative Phase Analysis Using the Rietveld Method," I. Appl. Cryst, 21, (1988), 8691.

11. M. A. Hicks and A. C. Pickard, "A Comparison of theoretical and experimental methods of calibrating the electrical potential drop technique for crack length determination," Int. J. Fracture, 20, (1982), 91-101.

12. A. J. Manning, Development of a Polycrystalline Ni Base Superalloy for Gas Turbine Disc Application, ( $\mathrm{PhD}$ Thesis, University of Cambridge, U.K., 1999).
13. D. K. Skelton and D. M. Knowles, "The Creep Fatigue of Turbine Disc Alloys," Proceedings of the $7^{\text {th }}$ International Fatigue Conference (June 1999, Beijing, P. R. China), 21112116.

14. J. F. Knott, "Models of Fatigue Crack Growth", Proceedings of a Conference on Fatigue Crack Growth, 1984, Ed. R. A. Smith, Cambridge, U.K. (September 1984), 31-52.

15. H. Riedel, Fracture at High Temperatures (Berlin, Germany: Springer-Verlag, 1987), 274-277.

16. H. Riedel, Fracture at High Temperatures (Berlin, Germany: Springer-Verlag, 1987), 59-60, 112-114.

17. H. Ghonem and D. Zheng, "Depth of intergranular oxygen diffusion during environmental-dependent fatigue crack growth in alloy 718," Mat. Sci. Eng., A150, (1992), 151-160.

18. H. Ghonem, T. Nicholas, and A. Pineau, "Elevated Temperature Fatigue Crack Growth in Alloy 718 - Part II: Effects of Environmental and Material Variables," Fatigue Fract. Engng. Mater. Struct, 16, (6), (1993), 577-590.

19. E. Andrieu et al, "Intergranular Crack Tip Oxidation Mechanism in a Nickel-Based Superalloy", Mat. Sci. Eng., A154, (1992), 21-28.

20. K. D. Challenger, R. P. Skelton, and J. S. Kamen, "The Effect of Oxidation on Fatigue Crack Growth in 2.25Cr-1Mo Steel at $525^{\circ} \mathrm{C}$ : A Metallographic Examination," Mat. Sci. Eng., 91, (1987), 1-6.

21. R. H. Bricknell, and D. A. Woodford, Acta Metall., "The Mechanism of Cavity Formation During high Temperature Oxidation of Nickel", 44, 1982, 257-264.

22. H. M. Lu et al, "Environmentally-Enhanced Cavity Growth in Nickel and Nickel-Based Alloys," Acta Mater., 44, (8), (1996), 3259-3266. 